\title{
Thermal Management in Traction Applications as a Constraint Optimal Control Problem
}

\author{
Joris Lemmens and Johan Driesen \\ KU Leuven, Dept. of Electrical Engineering ESAT-ELECTA \\ Kasteelpark Arenberg 10 \\ B-3001 Leuven, Belgium \\ Email: joris.lemmens@esat.kuleuven.be
}

\author{
Piet Vanassche \\ Triphase NV \\ Romeinse Straat 18 \\ B-3001 Leuven, Belgium \\ Email: piet.vanassche@ triphase.com
}

\begin{abstract}
In traction applications, electrical drivetrain components are subjected to unpredictable load and temperature variations depending on the driving cycle and ambient conditions. As performance and power density requirements are getting increasingly stringent, the power electronic devices and electromagnetic actuators are stressed heavily due to temperature cycling effects and face the risk of overheating, compromising lifetime and reliability. To protect the drivetrain from thermally induced failure, a model-based thermal management strategy is proposed in this paper. Critical component temperatures are calculated online with a combined loss and thermal model and are limited progressively by applying constraints to loss-influencing operating variables. Starting from the requested torque, the $d q$-current setpoint calculation is formulated as a constraint optimization problem in order to protect all drivetrain components while maximizing overall efficiency over the entire torquespeed operating range, including field weakening at elevated speed. Unlike conventional approaches, which are often adhoc or based on de-rating, the proposed strategy allows the drivetrain to operate safely at maximum performance limits, without unnecessarily degrading performance.
\end{abstract}

\section{INTRODUCTION}

Drivetrains for (hybrid) electric vehicles continue to evolve towards higher performance and power density specifications resulting in increased switching frequencies and operating temperatures. On the other hand, demands regarding reliability, safety and lifetime expectancy of electrical drives become increasingly stringent. In power electronics, most failure mechanisms are related to overheating and thermal cycling effects which cause mechanical stress due to different thermal expansion of bonded materials. At the motor side, excessive temperature rise will affect the stator winding insulation and permanent magnet properties, degrading lifetime and performance considerably.

Traction applications are characterized by a wide range of driving cycles. Torque and speed operating points depend on numerous factors such as the type and gradient of the road, driving style and vehicle load. The sequences of heavy acceleration followed by regenerative braking put large thermal stress on the converter semiconductors and passive components [1]. Moreover, the ambient temperature conditions can vary significantly over the seasons. For industrial drives in stationary or servo applications, load cycles and ambient conditions show less variations, resulting in predictable thermal behavior. In many cases, thermal protection of the drive is guaranteed by ad-hoc methods such as appropriate (over)sizing of the motor and converter, setting a fixed torque limit or monitoring heat sink or motor temperature. However, the large and unpredictable variation in load and ambient conditions in traction applications makes the temperature profile impossible to predict. Hence, the ad-hoc thermal protection approaches used for industrial drives fall short for traction applications. Oversizing the motor and converter for worst case conditions would result in a cost-ineffective and bulky solution. Applying fixed current safety limits would degrade short-time overload performance. A more advanced thermal management strategy is necessary, but direct measurements of critical component temperatures are difficult and heat sink or motor frame measurements do not provide the necessary time-critical information. A model-based temperature estimation of the inaccessible components can offer a solution. By calculating the average semiconductor loss over one electric period and applying this to the power module's thermal resistance network, the average junction temperature can be estimated relatively accurate [2]. However, the problem of this method is that it assumes a high electrical frequency and that formulae for average power loss can be used. It is known that the estimation errors increase considerably at low speed and stall torque conditions. This type of load is quite common in traction applications, for instance in uphill starts or hill hold mode which even requires DC-current. In a multi-chip power module typically used in a three-phase inverter, DC-current puts continuous thermal stress on the conducting IGBTs and freewheeling diodes according to the phase current direction [3]. Compared to AC-conditions, the power dissipation is divided over less components which results in increased junction temperatures for equal RMScurrents. The previously referenced temperature calculation method will underestimate the junction temperatures considerably which can lead to catastrophic failures.

This paper proposes a model-based strategy that performs a temperature protection for each individual component to allow safe operation under all conditions (including DC) without unnecessarily degrading performance. Related work [4]-[6] concerning active thermal control uses a similar model-based approach but can result in a sub-optimal operating point and a reduction of output torque before the actual performance 
limits are reached. The added value of the proposed strategy is that it goes further than merely adding a (current) limiter to a conventional motor control algorithm. It includes realtime thermal models of the drivetrain components combined with a thermal management strategy. In order to guarantee operation at maximum attainable efficiency and torque, the optimal $d q$-current setpoints inside the voltage and current constraint boundaries are calculated.

This paper continues with a brief conceptual overview of the strategy which was successfully implemented to a fieldoriented control algorithm for an interior permanent magnet synchronous motor (PMSM).

\section{OVERVIEW OF THE CONTROL STRATEGy}

A schematic representation of the control algorithm is shown in Fig. 1. In what follows, the main parts are elaborated.

\section{A. Real-time loss calculation and thermal models}

IGBT and freewheeling diode (FWDI) losses of a threephase inverter can be subdivided into conduction $\left(P_{c}\right)$, switching $\left(P_{s w}\right)$ and diode reverse recovery $\left(P_{r r}\right)$ loss. The realtime model implements an averaged power loss calculation per switching timecycle $T_{s}$, giving sufficient details on temperature cycling effects. Component current and temperature dependencies (from datasheets) are stored as polynomials. Fig. 2 shows the IGBT collector-emitter voltage $V_{c e}$. Identical functions are constructed for the IGBT switching losses $E_{\text {on }}$ and $E_{o f f}$, the FWDI emitter-collector voltage $V_{e c}$ and reverse recovery loss $E_{o f f}$.

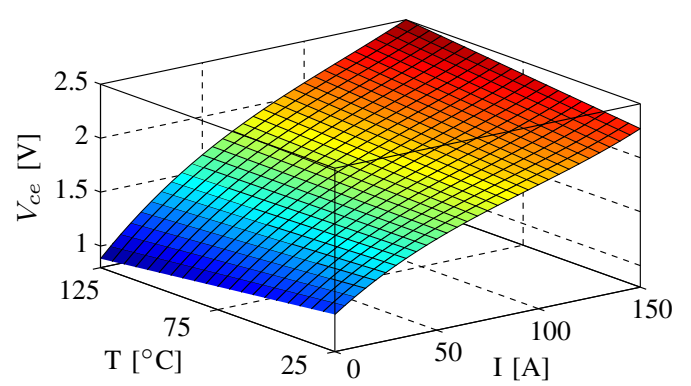

Fig. 2. IGBT collector-emitter voltage polynomial:

$V_{c e}=1.21+9.93 e^{-3} I-1.88 e^{-3} T-2.54 e^{-5} I^{2}+3.22 e^{-5} I T$.

The device conduction currents (Fig. 3) can be derived from the measured terminal currents $i_{a b c}$. Depending on the

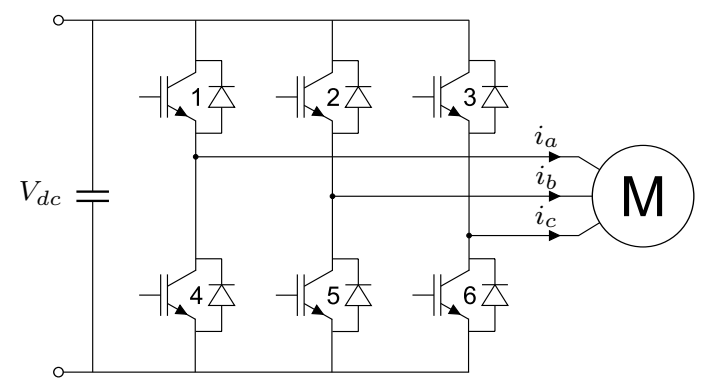

Fig. 3. Three-phase inverter, IGBT and FWDI numbering convention. current direction $s(i)(+1$ or -1 for positive or negative currents respectively), the FWDI or IGBT will conduct. For the first inverter leg this results in:

$$
\begin{aligned}
& {\left[\begin{array}{c}
i_{i g b t, 1} \\
i_{i g b t, 4}
\end{array}\right]=\frac{1}{2} \cdot\left[\begin{array}{c}
1+s\left(i_{a}\right) \\
1-s\left(i_{a}\right)
\end{array}\right] \cdot i_{a}} \\
& {\left[\begin{array}{c}
i_{f w d i, 1} \\
i_{f w d i, 4}
\end{array}\right]=\frac{1}{2} \cdot\left[\begin{array}{c}
1-s\left(i_{a}\right) \\
1+s\left(i_{a}\right)
\end{array}\right] \cdot i_{a}}
\end{aligned}
$$

The average conduction loss over one switching cycle depends on the actual duty cycle value $\delta(+1$ to -1$)$. With $k=1$ for the devices at the upper side of the inverter bridge and $k=-1$ for the components at the lower side, the ratio between conduction time and switching period equals:

$$
\frac{T_{\text {cond }}}{T_{s}}=\frac{1+k \delta}{2}
$$

Furthermore, the switching loss depends on the actual DCbus Voltage $V_{d c}$ (relative to the nominal bus voltage $V_{r e f}$ ) and switching frequency $1 / T_{s}$. This results in the following equations for real-time loss calculation per component:

$$
\begin{gathered}
P_{c, i g b t}=V_{c e}(i, T) i \frac{T_{c o n d}}{T_{s}} \\
P_{c, f w d i}=V_{e c}(i, T) i \frac{T_{c o n d}}{T_{s}} \\
P_{s w, i g b t}=\left[E_{o n}(i)+E_{o f f}(i)\right] \frac{V_{d c}}{V_{r e f}} \frac{1}{T_{s}} \\
P_{r r, f w d i}=E_{r r}(i) \frac{V_{d c}}{V_{r e f}} \frac{1}{T_{s}}
\end{gathered}
$$

The losses for each component are applied to the thermal model in Fig. 4. It consists of datasheet provided junction to case $\left(Z_{j c}\right)$ and case to heatsink $\left(Z_{c f}\right)$ thermal impedances. The outcome yields the device-specific junction temperature rises relative to the measured heatsink temperature $T_{\text {fin }}$.

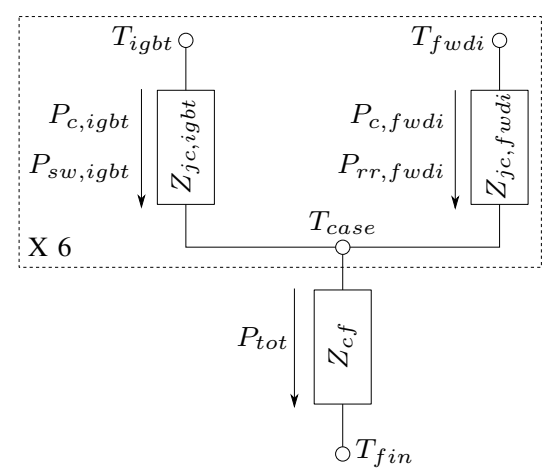

Fig. 4. Inverter transient thermal impedance network for real-time junction temperature calculation.

The main motor losses, copper $P_{c u}$ and iron loss $P_{\text {core }}$, are calculated using (8) and (9).

$$
\begin{gathered}
P_{c u}=R_{s}(T)\left(i_{d}^{2}+i_{q}^{2}\right) \\
P_{\text {core }}=\frac{\left(\omega L_{q} i_{q}\right)^{2}+\left(\omega L_{d} i_{d}+\omega \Psi\right)^{2}}{R_{c}(\omega)}
\end{gathered}
$$




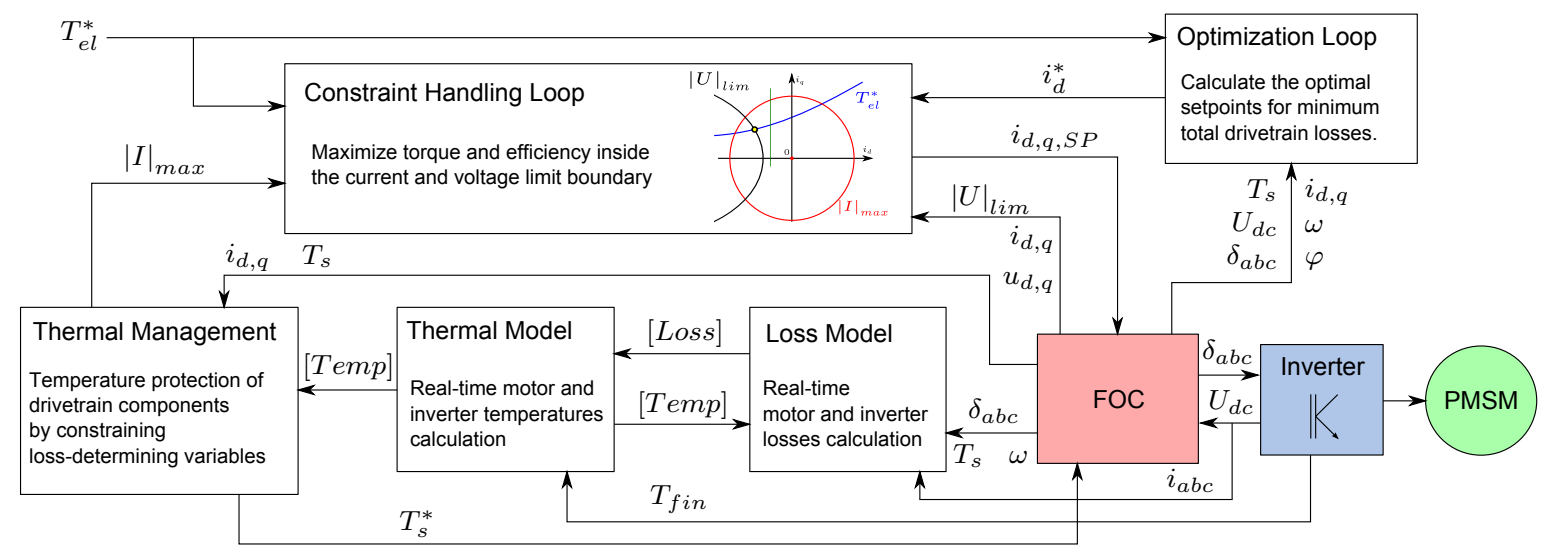

Fig. 1. Block diagram of the proposed PMSM control algorithm.

In order to include the temperature dependence of the stator resistance $R_{s}$, a temperature feedback from the thermal model is used. The direct and quadrature currents $i_{d}$ and $i_{q}$ are obtained from the measured terminal currents and the rotor position. $P_{\text {core }}$ is found as the ratio of back-emf squared and the equivalent iron loss resistance $R_{c}$. This parameter is determined according to the method described in [7], resulting in a value depending on the electrical frequency $\omega$ shown in Fig. 5. All other motor parameters including rotor flux linkage $\Psi$, direct and quadrature inductances $L_{d}$ and $L_{q}$ are obtained from experiments.

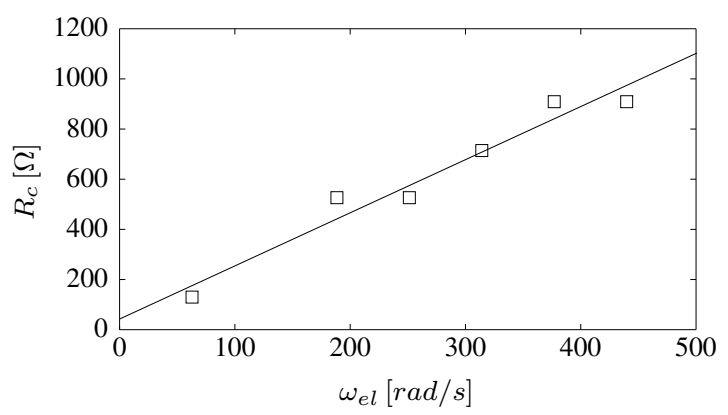

Fig. 5. Equivalent iron loss resistance.

The motor losses and ambient conditions are the input variables to a real-time thermal model of the PMSM which is written in a state-space form with parameters derived from motor geometry and material data [8]. Furthermore, a number of heat transfer parameters such as the natural and forced frame to ambient convection coefficients are determined experimentally. This allows us to create a network of thermal resistances and capacitances in which the nodes represent the motor subpart temperatures of interest (yoke, rotor, winding,...). The model includes a Kalman filter taking into account inaccurate or slow measurements, if available. These measurements help to improve the low-frequency accuracy of the actual estimates. As shown in Fig. 6 for a constant load situation, good agreement between measured and estimated motor temperatures has been obtained.

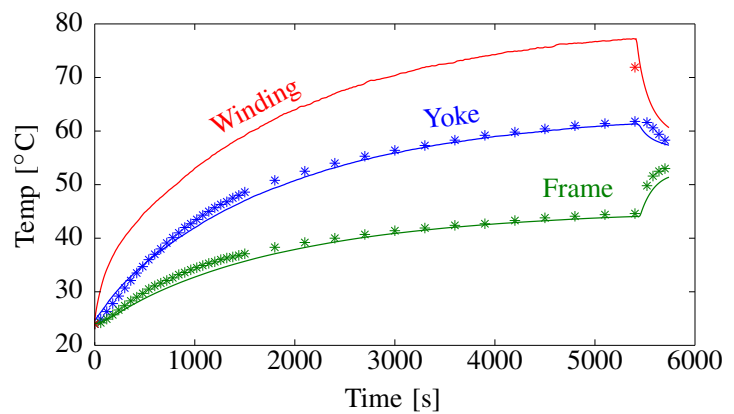

Fig. 6. Motor thermal model validation - Calculated and measured (*) temperatures at $1500 \mathrm{rpm} 70 \mathrm{Nm}$ (shutdown at $5400 \mathrm{~s}$ ).

\section{B. Efficiency Optimization}

The optimal operating regime for a drivetrain is essentially the one that minimizes its losses for a given torque request $T_{e l}^{*}$ (MEPNm: Maximum Efficiency per Nm). To this account, the system has some degrees of freedom available. Looking at the previously discussed loss equations and the torque equation,

$$
T_{e l}=p i_{q}\left(\Psi-\left(L_{q}-L_{d}\right) i_{d}\right)
$$

switching frequency, d-axis current and DC-bus voltage can be adjusted to control losses without affecting output torque. This paper elaborates the d-axis current optimization. Given the voltage and current boundaries, this can be formulated as a constraint optimization problem.

The overall drivetrain loss $P_{\text {loss }}$ and its components were already discussed in the previous paragraph. However, it should be noted that, in contrast to the thermal model, the optimization loop uses the inverter losses averaged over one electric period expressed by (12) to (15) with $\hat{i}$ the current amplitude in the abc-framework $\left(\hat{i}^{2}=\frac{2}{3}\left(i_{d}^{2}+i_{q}^{2}\right)\right), \hat{\delta}$ the duty cycle amplitude, svm the space vector modulation function and $\varphi$ the phase angle.

$$
\begin{aligned}
P_{i n v} & =6\left(\bar{P}_{c, i g b t}+\bar{P}_{c, f w d i}+\bar{P}_{s w, i g b t}+\bar{P}_{r r, f w d i}\right) \\
\bar{P}_{c, i g b t} & =\frac{1}{2 \pi} \int_{0}^{\pi} V_{c e}(i, T) \hat{i} \sin (x) \frac{1+\hat{\delta} s v m(x+\varphi)}{2} d x
\end{aligned}
$$




$$
\begin{gathered}
\bar{P}_{c, f w d i}=\frac{1}{2 \pi} \int_{\pi}^{2 \pi} V_{e c}(i, T)|\hat{i} \sin (x)| \frac{1+\hat{\delta} \operatorname{svm}(x+\varphi)}{2} d x \\
\bar{P}_{s w, i g b t}=\frac{1}{2 \pi} \int_{0}^{\pi}\left[\left(E_{o n}(i)+E_{o f f}(i)\right] \frac{V_{d c}}{V_{r e f}} \frac{1}{T_{s}} d x\right. \\
\bar{P}_{r r, f w d i}=\frac{1}{2 \pi} \int_{\pi}^{2 \pi} E_{r r}(i) \frac{V_{d c}}{V_{r e f}} \frac{1}{T_{s}} d x
\end{gathered}
$$

Solving (10) to $i_{q}$ and substituting into the overall loss expression, minimizing $P_{\text {loss }}$ can be reduced to a singlevariable $\left(i_{d}\right)$ problem. It amounts to finding a solution for (16). Using a Newton iteration this results in an adjustment $d i_{d, \text { opt }}$ of the previous setpoint $i_{d, 0}$ to find the new setpoint $i_{d}^{*}$.

$$
\begin{gathered}
\frac{\mathrm{d} P_{\text {loss }}}{\mathrm{d} i_{d}}=0 \\
\mathrm{~d} i_{d, o p t}=-\left.\frac{\frac{\mathrm{d} P_{l o s s}}{\mathrm{~d} i_{d}}}{\frac{\mathrm{d}^{2} P_{l o s s}}{\mathrm{~d} i_{d}^{2}}}\right|_{i_{d}=i_{d, 0}} \\
i_{d}^{*}=i_{d, 0}+\mathrm{d} i_{d, o p t}
\end{gathered}
$$

\section{Thermal management}

The purpose of this loop is to protect critical components of the drivetrain from overheating without unnecessarily degrading performance. This is done by monitoring the components' temperatures and constraining operating variables (Fig. 7). Like already stated in the introduction, low electrical frequencies put large thermal stress on the active semiconductors. In order to handle such worst-case (DC) conditions, the algorithm takes into account the highest instantaneous component temperature. However, at AC operation the thermal cycling ripple would propagate into the current limit and output torque. This is avoided with an asymmetric filter tracking the peak values to provide a smooth signal at moderate to high frequencies.

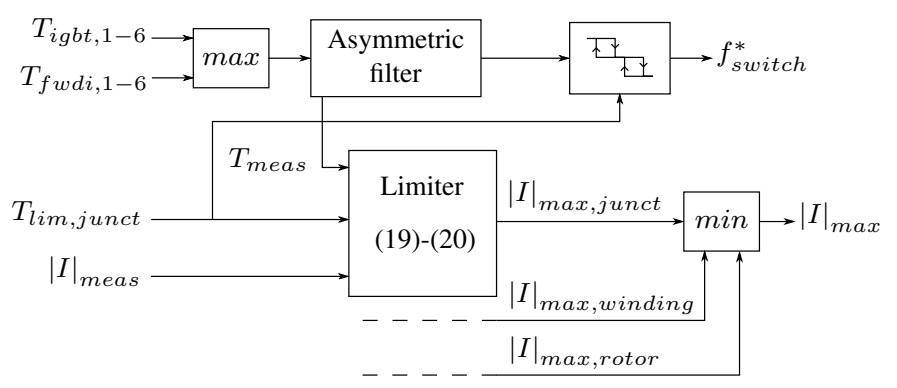

Fig. 7. Thermal management strategy.

When the maximum junction temperature approaches its safety limit $T_{\text {lim }}$, the first action is to reduce the switching frequency. A two-step hysteresis controller lowers the switching losses without affecting the output torque.

The temperature gradient $\frac{d T}{d t}$ is related to the actual power loss and the setpoint value is made proportional ( $\tau$ is a time constant) to the temperature margin according to (19).

$$
\frac{d T}{d t}_{S P}=\frac{T_{\text {lim }}-T_{\text {meas }}}{\tau}
$$

Temperature may rise fast in case of a large thermal reserve, but is limited progressively when the safety limit is approached. With (20), the current limit is calculated as an adjustment to the actual current amplitude $|I|_{\text {meas }}$ to correct the gradient error within a time constant $T_{c t r l}$.

$$
|I|_{\text {max }}=|I|_{\text {meas }}+\left[\frac{d T}{d t}_{S P}-\frac{d T}{d t}{ }_{\text {meas }}\right] \frac{T_{s}}{T_{c t r l}}
$$

An identical current limiting algorithm is applied to other drivetrain parts. Finally, the most stringent current limit $|I|_{\max }$ is transmitted to the constraint handling loop.

\section{Constraint handling loop}

This loop checks if the requested torque $T_{e l}^{*}$ and the optimal d-current setpoint $i_{d}^{*}$ are feasible given the maximum output voltage $|U|_{\text {lim }}=f\left(V_{d c}\right)$ and current limit $|I|_{\text {max }}$. First, the target changes in voltage, torque and d-current are computed:

$$
\begin{gathered}
d|U|_{S P}=|U|_{l i m}-|U| \\
d T_{e l, S P}=T_{e l}^{*}-T_{e l} \\
d i_{d, S P}=i_{d}^{*}-i_{d}
\end{gathered}
$$

The differential change of torque $d T_{e l}$ and voltage $d|U|$ can be written in terms of change in current $d i_{d}$ and $d i_{q}$ by taking the total derivative of the motor torque and voltage equations. With these equations, the discrete-time control strategy solves a constraint optimization problem in real-time. Each iteration, it calculates the current setpoint adjustments $d i_{d}$ and $d i_{q}$ that minimize $\left|d T_{e l, S P}-d T_{e l}\right|$ whereby:

$$
\begin{gathered}
d|U| \leq d|U|_{S P} \\
\left(i_{d, 0}+d i_{d}\right)^{2}+\left(i_{q, 0}+d i_{q}\right)^{2} \leq|I|_{\text {max }}^{2}
\end{gathered}
$$

Without going into detail, the strategy incorporates a priority-based algorithm to determine the required current setpoint adjustments within the boundaries of the constraint region in the $d i_{d} d i_{q}$-framework.

1) Voltage limiting: Apply field weakening at elevated speed to maintain control at all times.

2) Current limiting: Protect components.

3) Try to deliver the requested torque if possible. If not, maximize torque within the boundary.

4) Optimization: Try to meet $i_{d}^{*}$ as close as possible.

Fig. 8 shows one particular case in which the torque request is satisfied and $i_{d}^{*}$ is inhibited by the voltage limit.

Finally, the computed corrections are applied with a timeconstant $T_{c t r l}$ to generate the new current setpoints:

$$
\begin{aligned}
& i_{d, S P}=i_{d, S P, 0}+\frac{T_{s}}{T_{c t r l}} d i_{d} \\
& i_{q, S P}=i_{q, S P, 0}+\frac{T_{s}}{T_{c t r l}} d i_{q}
\end{aligned}
$$



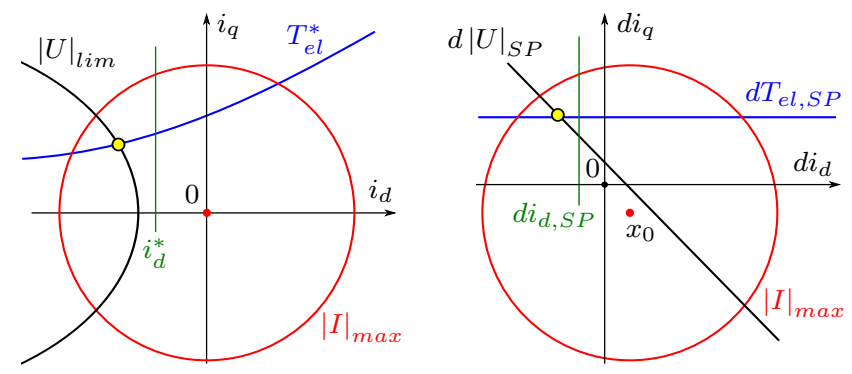

Fig. 8. Constraint handling; maximize torque and efficiency inside the current and voltage constraint region.

TABLE I

PMSM PARAMETERS

\begin{tabular}{cc}
\hline \hline Power & $11 \mathrm{~kW}$ \\
Pole Pairs & 3 \\
Inductance $L_{d}$ & $10 \mathrm{mH}$ \\
Inductance $L_{q}$ & $19 \mathrm{mH}$ \\
Phase Voltage Constant & $245 \mathrm{~V} / \mathrm{kRPM}$ \\
Phase Resistance & $0.336 \Omega$ \\
\hline \hline
\end{tabular}

\section{EXPERIMENTAL RESULTS}

The strategy is implemented on a Triphase rapid prototyping platform controlling a test setup (Fig. 9). It includes a $11 \mathrm{~kW}$ interior permanent magnet motor (Table I), a $17 \mathrm{kVA}$ threephase inverter and a torque-controlled DC machine. The DCbus of the inverter is powered directly at $600 \mathrm{~V}$.

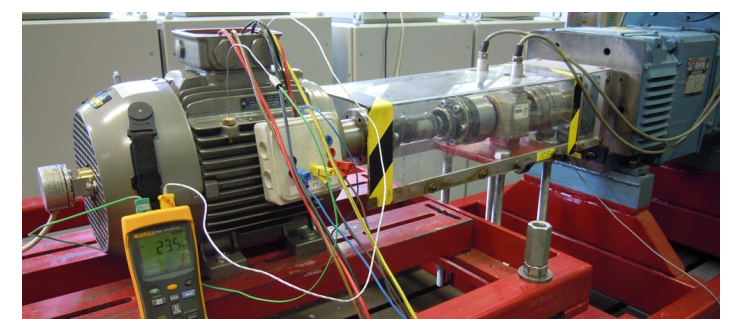

Fig. 9. Experimental setup.

\section{A. Efficiency Optimization}

Table II compares the proposed MEPNm (Maximum Efficiency per $\mathrm{Nm}$ ) algorithm with two more straightforward strategies. For a number of increasing speed setpoints at constant torque, the overall drivetrain loss is measured with a power analyzer at the dc-bus and a torque/speed transducer. As a reference, we take the $i_{d}=0$ control strategy. The MTPA (Maximum Torque per Ampere) strategy manages to lower the joule losses considerably by exploiting the PMSM reluctance torque. The MEPNm strategy reduces losses further, because it optimizes the overal drivetrain losses. The difference is more pronounced at higher speeds as iron loss increases. In absolute numbers, the MEPNm benefit over MTPA is quite small for this motor. The strategy will be particularly interesting for high-frequency motors with high specific core losses.
TABLE II

LOSS MINIMIZATION AT $70 \mathrm{NM}$

\begin{tabular}{c|c|cc|cc} 
& $i_{d=0}$ & \multicolumn{2}{|c|}{ MTPA } & \multicolumn{2}{|c}{ MEPNm } \\
$\begin{array}{c}\text { Speed } \\
{[\mathrm{RPM}]}\end{array}$ & $P_{\text {loss }}$ & $\Delta P_{i d=0}$ & $i_{d}$ & $\Delta P_{i d=0}$ & $i_{d}$ \\
\hline 200 & 851 & -114 & -8.9 & -115 & -9.3 \\
400 & 915 & -125 & -8.9 & -128 & -9.7 \\
600 & 985 & -133 & -8.9 & -136 & -10.1 \\
800 & 1049 & -141 & -8.9 & -149 & -10.5 \\
1000 & 1112 & -145 & -8.9 & -154 & -11.0 \\
1200 & 1178 & -154 & -8.9 & -163 & -11.5
\end{tabular}

\section{B. Driving cycle}

In order to test the thermal management strategy under dynamic load conditions, a driving cycle was emulated on the experimental setup. The test cycle in Fig. 10 is based on the US06 Supplemental Federal Test Procedure (SFTP), representing dynamic high-acceleration driving behavior. This trajectory is used as a speed setpoint for the controller. The load machine torque is proportional to the motor speed $(0.055$ $\mathrm{Nm} / \mathrm{RPM})$. In the first part $(0-280 \mathrm{~s})$ of the test cycle , the drivetrain is able to deliver the necessary torque to track the speed setpoint. As component temperatures increase towards the chosen limit of $45^{\circ} \mathrm{C}$, the switching frequency is reduced in two steps from 10 to $5 \mathrm{kHz}$. This appears as a notch in the inverter loss and junction temperature plots. After approximately 280 seconds, the IGBT temperatures closely approach the $45^{\circ} \mathrm{C}$ limit. The gradient is limited progressively by the current constraint until the temperature maxima reach the limit. From the speed plot, it is clear that the drivetrain is now unable to deliver the necessary torque to track the speed setpoint. However, it will continue to operate at maximum attainable output torque. After 400 seconds, the stator winding reaches the limit set at $43^{\circ} \mathrm{C}$. Now, the current (torque) is limited further to prevent the winding from overheating. In the last part of the test cycle (500-600 s), temperatures have dropped and a dynamic sequence can be tracked perfectly.

\section{DC Conditions}

An important feature of the thermal management strategy is that it protects individual components from overheating at DC conditions. This type of load is applied to the test setup by mechanically blocking the rotor and requesting a large torque of $65 \mathrm{Nm}$. Fig. 11 shows how the controller reacts to this. The actual rotor position implies that the third inverter leg (phase c) in Fig. 3 conducts the largest DC current. Since this current has a positive sign, IGBT 3 and FWDI 6 show the largest temperature increase. The thermal management strategy first reduces the switching frequency (notice the temperature notches). Next, a current limit is imposed to gradually limit the temperature of FWDI 6 at $55^{\circ} \mathrm{C}$.

\section{ConClusion}

This paper proposed a model-based thermal management strategy for traction applications. The algorithm protects critical drivetrain components from overheating without unnecessarily degrading performance. This is done by including 

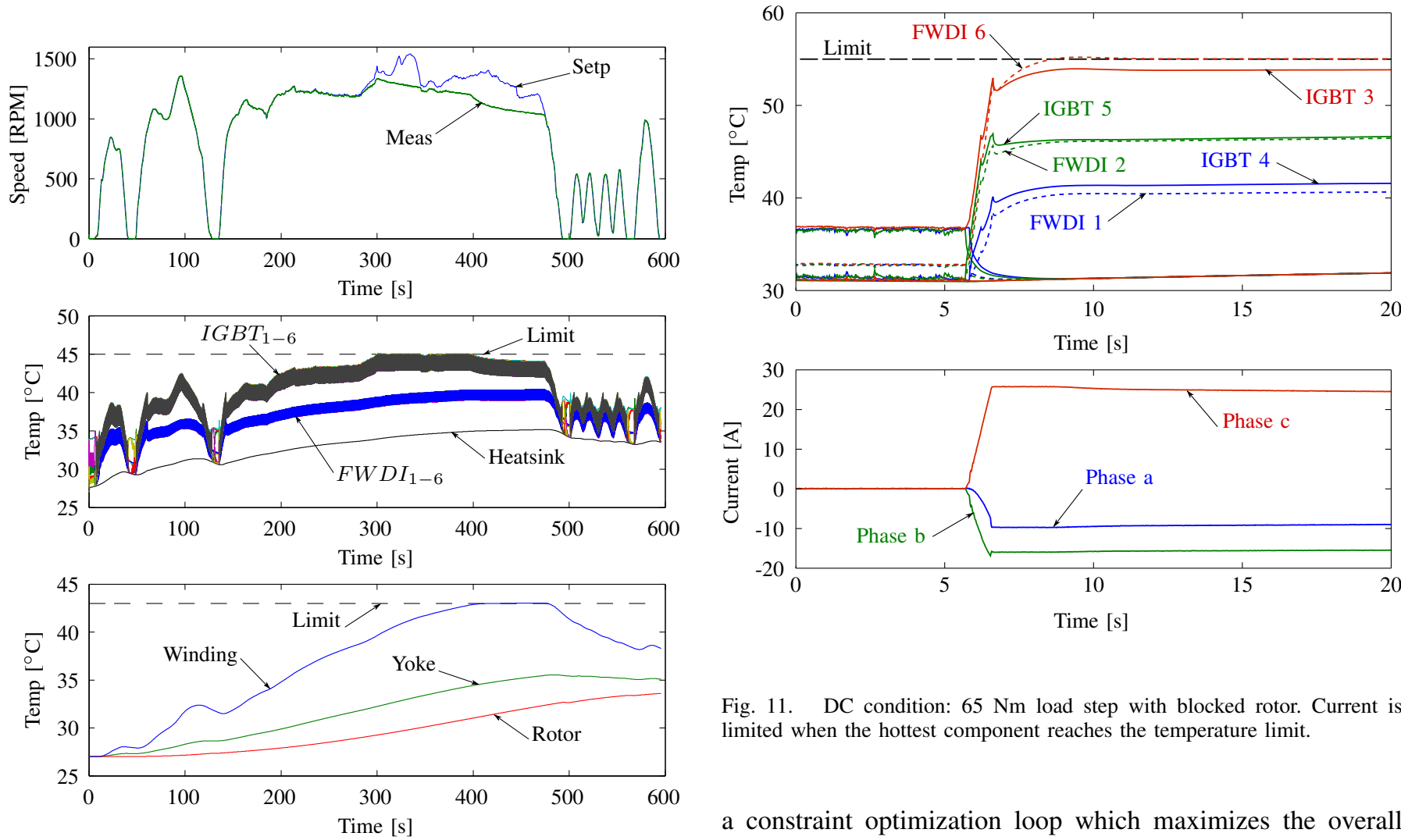

Fig. 11. DC condition: $65 \mathrm{Nm}$ load step with blocked rotor. Current is limited when the hottest component reaches the temperature limit

a constraint optimization loop which maximizes the overall efficiency and torque inside the voltage and current constraint region. The strategy has been validated on an experimental setup for a dynamic driving cycle. Moreover, stall torque (DCcurrent) conditions, known for heavily stressing semiconductor components, were handled successfully. Regarding efficiency, an improvement compared to conventional strategies was measured over a wide operating range.

\section{REFERENCES}

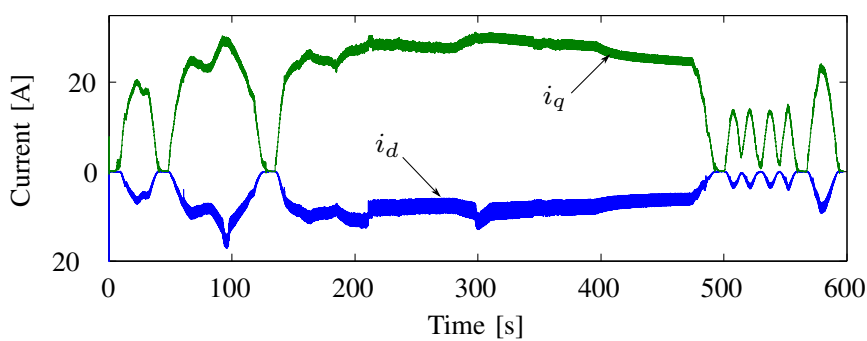

[1] D. Hirschmann, D. Tissen, S. Schroder, and R. De Doncker, "Reliability prediction for inverters in hybrid electrical vehicles," Power Electronics, IEEE Transactions on, vol. 22, no. 6, pp. 2511 -2517, nov. 2007.

[2] "General considerations for igbt and intelligent power modules," Application note, Mitsubishi Electric, pp. 8-13, sep 1998.

[3] L. Wei, R. Kerkman, R. Lukaszewski, B. Brown, N. Gollhardt, and B. Weiss, "Junction temperature prediction of a multiple-chip igbt module under dc condition," in Conf. Rec. IEEE-IAS Annu. Meeting, vol. 2, oct. 2006, pp. $754-762$.

[4] D. Murdock, J. Torres, J. Connors, and R. Lorenz, "Active thermal control of power electronic modules," Industry Applications, IEEE Transactions on, vol. 42, no. 2, pp. 552 - 558, march-april 2006.

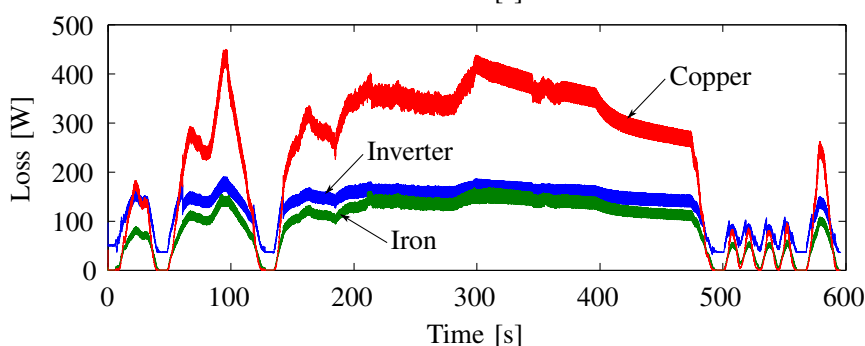

[5] V. Blasko, R. Lukaszewski, and R. Sladky, "On line thermal model and thermal management strategy of a three phase voltage source inverter,' in Conf. Rec. IEEE-IAS Annu. Meeting, 1999, pp. $1423-1431$.

[6] M. Weckert and J. Roth-Stielow, "Chances and limits of a thermal control for a three-phase voltage source inverter in traction applications using permanent magnet synchronous or induction machines," in Proceedings of the 14th European Conference on Power Electronics and Applications (EPE 2011), 2011.

[7] N. Urasaki, T. Senjyu, and K. Uezato, "A novel calculation method for iron loss resistance suitable in modeling permanent-magnet synchronous motors," Energy Conversion, IEEE Transactions on, vol. 18, no. 1, pp. $41-47$, mar 2003

Fig. 10. US06 driving cycle emulation with load torque proportional to speed $(0.055 \mathrm{Nm} / \mathrm{RPM})$. The junction temperature limit is set at $45^{\circ} \mathrm{C}$ and the stator winding limit at $43^{\circ} \mathrm{C}$.

[8] G. Demetriades, H. de la Parra, E. Andersson, and H. Olsson, "A realtime thermal model of a permanent-magnet synchronous motor," Power Electronics, IEEE Transactions on, vol. 25, no. 2, pp. $463-474$, feb. 2010 . 